\title{
Study of Microstrip Dual-Band Band Pass Filter
}

\author{
Anciline $\mathrm{V}^{\mathrm{a}, 1}$, and Maheswari $\mathrm{S}^{\mathrm{b}}$ \\ $a_{P G}$ Scholar, Dept of ECE, Panimalar Engineering College, Chennai

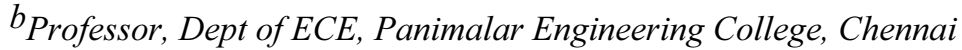

\begin{abstract}
The main component widely used in wireless communication system is dual-band band pass filter. This band pass filter is intended in many ways and some are microstrip, waveguide, etc. The dual-band will works in two different frequency ranges which will provide a huge application. This paper compares different microstrip dual-band band pass filter based on the techniques, insertion loss, frequency, etc.,
\end{abstract}

Keywords. Microstrip, Dual-band band pass filter, Stepped-Impedance resonator.

\section{Introduction}

Microstrip dual-band band pass filters have many advantages like low insertion loss, wide stop band bandwidth, compactness, sharp roll-off, and it has a large application in microwave communication. The most effective way for connecting two BPFs with different pass bands in parallel [4]. Microstrip is a category of electrical transmission line, with the help of this technology microstrip might be manufacture, where the conductor was segregated from a ground plane by a dielectric layer. The dielectric layer is known as substrate. To transfer microwave frequency signals microstrip-lines are employed. The microwave elements such as antennas, power dividers, filters, couplers, and so on, might be set-up from microstrip, with the appearance tool available as the model of metallization over the substrate. The main advantage of microstrip is less exorbitant than the conventional waveguide technology, compactness and far lighter. The band pass filter might be made by cascade the high pass filter to the low pass filter, or antipodal. The main purpose of such filter is to restrain the bandwidth of the output signal to the band allotted for the communication. The key component, for recognition of a dual-band wireless communication system is dual-band band pass filter [3]. At first dual-band filter report, the two separate filters which are straightly cascaded with two specified pass bands. But in this case, we got a large overall size and high insertion loss in its filter block [1].

\footnotetext{
${ }^{1}$ Anciline V, PG scholar, Dept of ECE, Panimalar Engineering College, Chennai; E-mail: ancilinevargees741@gmail.com
} 


\section{Related works}

Sheng Sun et.al [1] In this work they focused on, compact dual-band microstrip bandpass filter, without any exterior impedance matching block, works at 2.4 and $5.2 \mathrm{GHz}$ with FBW of $7.0 \%$ and $4.0 \%$. Modified $\lambda / 2$ stepped impedance resonator along the bending arrangement was set-up for simultaneous execution of double resonance at these two prescribed frequencies thereby keeps down the full extent $10.2 \times 12.3 \mathrm{~mm}^{2}$. To keep down the return losses under twain dual pass band, the collateral open-strip line is correctly characterized. The enhanced results, express acceptable dual-band filtering execution with return loss exceeding $20 \mathrm{~dB}$ while the assessed insertion losses were $1.8 \mathrm{~dB}$ as well as $2.9 \mathrm{~dB}$ by using WK-3000 substrate.

Yue Ping et.al [2] In this paper they fully focused on, by using SIR, a microstrip $\mathrm{BPF}$ was intended in low-temperature co-fired ceramic technology in order to dual-band implementation upon two prescribe frequencies $2.4 \mathrm{GHz}$ and $5.2 \mathrm{GHz}$. The paradigm of the bandpass filter reached the insertion loss of $0.42 \mathrm{~dB}$ as well as $0.91 \mathrm{~dB}$, return loss of -29 as well as $-40 \mathrm{~dB}$ likewise bandwidth of $14.2 \%$ as well as $12 \%$. The bandpass filter is additionally measured for a unique package clarification of dual-band radio transmitter and receiver.
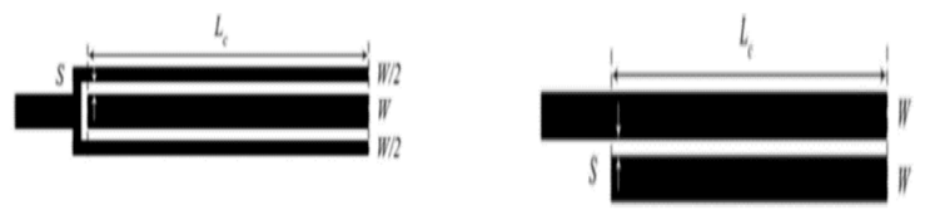

Figure 1a. Coupling scheme novel

Figure 1b. Coupling scheme normal

Chao-Hsing et.al [3] By using net-type resonators, a fresh dual-band microstrip BPF is evolved at frequencies $\mathrm{f}_{1}=1 \mathrm{GHz}$ moreover $\mathrm{f}_{2}=2 \mathrm{GHz}$. The trial basis demonstrated by using the RO4003 substrate. The measured result of the improved filter is an acceptable execution with the reproduced result via full-wave electromagnetic simulator. With return loss more than somewhat $12.6 \mathrm{~dB}$, also insertion loss of $2.65 / 2.44 \mathrm{~dB}$ with FBW is 4.6/4.8\%. The quality factor is 20.7/19.6 for the intended filter with the size of $41.83 \times 31.73 \mathrm{~mm}^{2}$.

Runqi Zhang et.al [4] are suggested a compress dual-band BPF, by using coupled three-portion stepped-impedance resonators, with the frequency $0.61 \mathrm{GHz}$ and $1.36 \mathrm{GHz}$. To get the input admittance, the even-odd mode scrutiny way was utilized. To analysis the filtering execution also the exactness of the submitted scheme principle, prototype dual-band filter turned out to be intended and fabricated. The resulted insertion loss is $0.45 / 0.75 \mathrm{~dB}$ with FBW of $32.3 / 10.5 \%$ with the transmission line theory technique.

B.A. Belyaev et.al [5] This paper is mainly focused on the quality factor. Based on interdigital structure, a novel compact microstrip resonator is suggested. The quality factor of the resonator has many times outnumbering the same resonators which are already present. By enlarging the count of pins in the interdigital arrangement, the dimension of the resonator might be decreased with notable surge in quality factor. On the base of suggested structure, a bandpass filter of 4-pole with size $4.6 \mathrm{~mm} \times 10.0 \mathrm{~mm}$ and a central frequency $900 \mathrm{MHz}$ was intended and fabricated, with the return loss of $-13 \mathrm{~dB}$ and insertion loss of $1.7 \mathrm{~dB}$ with FBW of $20 \%$. The unloaded quality factor is 120 for this design. 


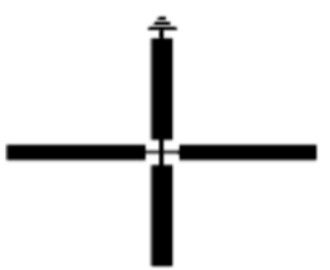

(a)

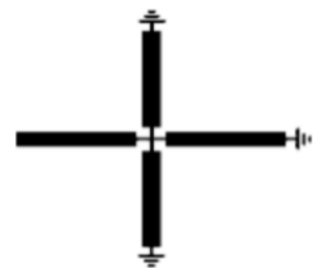

(b)

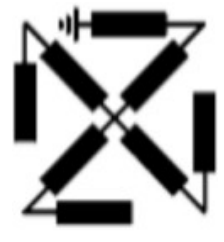

(b)

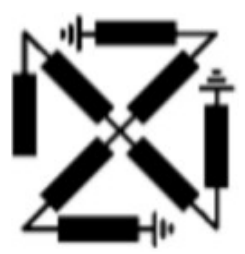

(d)

Figure 2. (a) and (c) Cross resonators, (b) and (d) Net-type resonator.

Chi-Feng Chen et.al [6] This paper focused on, a size reduced sept-band bandpass filter over elastic passband sharing were suggested with frequencies are 1.05/1.3/1.5/2.05/2.35/2.85GHz. Whole passbands might be completely controlled and drawn autonomously, by initiating multiple coupling paths. The initial and final resonators were utilized to generate other passbands and as well serve as the input as well as output paring structure for the other passbands. So, extra functioning bands might be acquired without expanding the circuit area. The exceptional arrangement of resonator might assist to decrease filter space of $0.027 \lambda_{\mathrm{g}}{ }^{2}$ as well as produce extra functioning bands with FBW of 8/4/5/7.5/4.5/5.5/6.5\% with the help of Agilent N5230A.

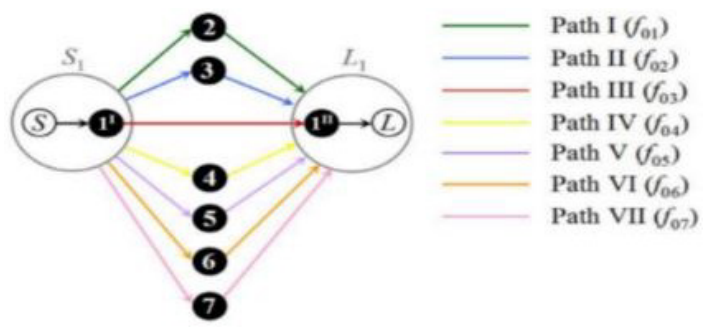

Figure 3. Coupling structure of sept-band bnadpass filter.

Chuantao Cai et.al [7] This paper is focused on, a new design version of microstrip wideband balun bandpass filter is suggested over frequency $1 \mathrm{GHz}$. The antiphase signals might be purchased at two output ports of a balun, via utilizing standing-wave attribute 
of voltage distribution beside an open circuited $\lambda / 2$ microstrip transmission line. To obtain a balun bandpass filter with two characteristics of balance execution and wideband filtering properties, by proper paring topologies amid the open circuited half wavelength microstrip transmission line, also the multi-manner resonators are selected. A balun bandpass working at $1 \mathrm{GHz}$ with an $30 \%$ of FBW was intended, executed also evaluated. Twain the measured as well as simulation outcome of intended balun bandpass filter are gives with acceptable assents of return loss better than $19 \mathrm{~dB}$ and insertion loss of $0.8 \mathrm{~dB}$ with the size of $0.586 \times 0.317 \lambda_{\mathrm{g}}{ }^{2}$. This balun band pass filter exhibits not only a high selectivity filtering performance with two common TZs of $\mathrm{S}_{21}$ and $\mathrm{S}_{31}$ external passbands, but also an acceptable balance performance over $0.5 \mathrm{~dB}$ amplitude instability also $5^{\circ}$ phase instability, by using the Rogers RO4003C substrate.

Roberto Gomez-Garcia et.al [8] with the help of Agilent E8361A, a regular quasireflection less dissimilarity mode bearing was suggested for microwave planar steadied single/dual-band BPF at frequency $2.82 \mathrm{MHz}$ and $3.21 \mathrm{MHz}$. Two proof-of-principle microstrip prototypes containing of $3 \mathrm{GHz}$ second order single band and $2.85 / 3.15 \mathrm{GHz}$ $1^{\text {st }}$ order dual-band bandpass filter with insertion loss $1.9 / 1.7 \mathrm{~dB}$ with FBW of $5.2 / 5.1 \%$ have been improved and simulated.

Xiaohu Wu et.ai [9] This paper is the first to do manifestation of broadcast as well as consistent all band quasi-absorptive filters that might be intended to haphazardly high order with help of Rogers $4003 \mathrm{C}$ substrate and the frequency is $2.2 \mathrm{GHz}$ and $2.76 \mathrm{GHz}$. The suggested quasi-absorptive filter contains of an absorptive sections and bandpass sections. In additional to eliminate the out-of-band reflection, the adsorptive sections determine the passband bandwidth. In additional to determine the out-of-band roll-off, bandpass section determine the order of the filter might be haphazardly enhanced do not have disturbing the filter bandwidth through cascading extra bandpass sections. A group of $2.45 \mathrm{GHz}$ one, two, trio pole quasi-absorptive microstrip bandpass filter are intended also evaluated. Across the passband and the stop band, the filter shows simultaneous input and output absorption. Measurement results are giving the acceptable difference over the simulation and authenticate the suggested purpose with insertion loss of $1.1 \mathrm{~dB}$ and FBW of $22.8 \%$.

Gen-Zhu Liang et.al [10] In accordance with loaded open/short-circuited stubs, a dual-wideband bandpass filter is suggested and analyzed with the Zeland IE3D and Agilent 5230A. The dual-band filter contains $2^{\text {nd }}$ order bandpass filter and the $3^{\text {rd }}$ order bandpass filter, any one that might be intended one by one. The bandwidth of two passband might be amended by regulate the impedance and the length of the stubs. A dual-band bandpass filter prototype works at $2.4 / 5.2 \mathrm{GHz}$ was intended proof with size $0.28 \times 0.20 \lambda_{\mathrm{g}}{ }^{2}$. It has $0.3 / 0.7 \mathrm{~dB}$ insertion loss and blanket bandwidth of $51.9 \%(2.4 \mathrm{GHz})$ as well as $23.3 \%(5.2 \mathrm{GHz})$ and return loss is $22.1 / 20.8 \mathrm{~dB}$. In the absence of contract paring gap amid resonators, the filter structure was effortless to fabricate.

\section{Literature survey}

Table 1. Comparison of different microstrip dual-band Band pass Filters

\begin{tabular}{cccccc}
\hline $\begin{array}{c}\text { S. } \\
\text { No }\end{array}$ & \multicolumn{1}{c}{ Technology } & $\begin{array}{c}\text { Insertion } \\
\text { Loss dB }\end{array}$ & Size & Frequency & FBW\% \\
\hline$[1]$ & Modified $\lambda / 2$ SIR & $1.8 / 2.9$ & $10.2 \times 12.3 \mathrm{~mm}^{2}$ & $2.4 / 5.2 \mathrm{GHz}$ & $7.0 / 4.0$ \\
{$[2]$} & Single-layer LTCC & $0.42 / 0.91$ & - & $2.4 / 5.2 \mathrm{GHz}$ & $14.2 / 12$
\end{tabular}




\begin{tabular}{|c|c|c|c|c|c|}
\hline [3] & Net-type resonator & $2.65 / 2.44$ & $41.83 \times 31.73 \mathrm{~mm}^{2}$ & $1 / 2 \mathrm{GHz}$ & $4.6 / 4.8$ \\
\hline [4] & Coupled 3-section SIR & $0.45 / 0.75$ & - & $0.61 / 1.36 \mathrm{GHz}$ & $32.3 / 10.5$ \\
\hline [5] & $\begin{array}{l}\text { Novel microstrip } \\
\text { resonator- interdigital } \\
\text { structure }\end{array}$ & 1.7 & $10 \times 4.6 \mathrm{~mm}$ & $900 \mathrm{MHz}$ & 20 \\
\hline [6] & Multiple coupling path & - & $0.027 \lambda_{\mathrm{g}}$ & $\begin{array}{l}1.05 / 1.3 / 1.5 / 1.8 / 2 \\
.05 / 2.35 / 2.85 \mathrm{GHz}\end{array}$ & $\begin{array}{c}8 / 4 / 5 / 7.5 / 4.5 / \\
5.5 / 6.5\end{array}$ \\
\hline [7] & $\begin{array}{l}\text { Standing-wave property } \\
\text { of voltage distribution } \\
\text { along an open-circuited } \\
\lambda / 2 \text { microstrip } \\
\text { transmission line }\end{array}$ & 0.8 & $0.586 \times 0.317 \lambda_{\mathrm{g}}$ & $1 \mathrm{GHz}$ & 30 \\
\hline [8] & $\begin{array}{l}\text { Symmetrical quasi- } \\
\text { reflection less } \\
\text { differential-mode }\end{array}$ & $1.9 / 1.7$ & - & $2.82 / 3.21 \mathrm{MHz}$ & $5.2 / 5.1$ \\
\hline [9] & $\begin{array}{l}\text { Distributed and } \\
\text { symmetrical quasi- } \\
\text { absorptive filter }\end{array}$ & 1.1 & - & $2.2 / 2.76 \mathrm{GHz}$ & 22.8 \\
\hline [10] & $\begin{array}{l}\text { Loaded open/short } \\
\text { circuited studs }\end{array}$ & $0.3 / 0.7$ & $0.28 \times 0.20 \lambda_{\mathrm{g}}$ & $2.4 / 5.2 \mathrm{GHz}$ & $51.9 / 23.3$ \\
\hline
\end{tabular}

\section{Conclusion}

Wide band and dual-band filters are widely used in wireless application. Microstrip dualband bandpass filter provides compactness, low cost and easy to fabricate. This paper compares the parameters like operating frequency, insertion loss, fractional bandwidth, technique and size of different microstrip dual-band BPF.

\section{Reference}

[1] Sheng Sun, Lei Zhu., Compact Dual-Band Microstrip Band pass Filter without External Feeds. IEEE, Vol. 15, No. 10, October 2005.

[2] Yue Ping Zhang, Mei Sun., Dual-band Microstrip Bandpass Filter Using Stepped-Impedance Resonators with New Coupling Schemes. IEEE, Vol. 54, No. 10, October 2006.

[3] Chao-Hsiung Tseng, Hsin-Yung Shao. ,A New Dual-band Microstrip Bandpass Filter Using Net-Type Resonators. IEEE, Vol 20, No. 4, April 2010.

[4] Runqi Zhang, Lei Zhu. ,Design of a Compact Dual-band Bandpass Filter Using Coupled SteppedImpedance Resonators. IEEE, Vol. 24, No. 3, March 2014.

[5] B. A. Belyaev, A. M. Serzhantov, A. A. Leksikov, Ya F. Bal'va, An A. Leksikov. Novel High-Quality Compact Microstrip Resonator and its Application to Bandpass Filter. IEEE, Vol. 25, No. 9, September 2015.

[6] Chi-Feng Chen, Sheng-Fa Chang, Bo-Hao Tseng., Design of Compact Microstrip Step-Band Bandpass Filter With Flexible Passband Allocation. IEEE, Vol. 26, No. 5, May 2016.

[7] Chuantao Cai, Jianpeng Wang, Lei Zhu, Wen Wu. ,A New Approach to Design Microstrip Wideband Balun Bnadpass Filter,. IEEE, Vol. 26, No. 2, February 2016.

[8] Roberto Gomez-Garcia, Jose-Maria Munoz-Ferreras, Wenjie Feng, Dimitra Psychogiou. . Balanced Symmetrical Quasi-Reflection less Single- and Dual-band Bandpass Filters. IEEE, Vol. 28, No.9, September 2018.

[9] Xiaohu Wu, Yingsong Li, Xiaoguang Liu., High-Order Dual-band Quasi-Absorptive Microstrip Coupled-Line Bandpass Filters. IEEE.

[10] Gen-Zhu Liang, Fu-Chang Chen. .A Compact Dual-Wideband Bandpass Filter Based on Open-/ShortCircuited Stubs. IEEE, Vol. 8, January 2020. 